\title{
PROTOTYPE PENGUKUR KUALITAS UDARA PM10 BERBASIS INTERNET Of THINGS (IoT)
}

\author{
Nur Arminarahmah ${ }^{1}$,Muhammad Rasyidan ${ }^{2}$ \\ Teknologi Informasi,Universitas Islam Kalimantan MAB \\ nur.armina@gmail.com \\ Teknologi Informasi,Universitas Islam Kalimantan MAB \\ mr.syidan@gmail.com
}

\begin{abstract}
ABSTRAK
Kondisi udara pada lingkungan tempat tinggal sudah mulai tercemar oleh polutan-polutan berupa asap pembakaran lahan, asap rokok, asap kendaraan bermotor serta banyak lagi sumber polutan yang lain.Untuk proses pendeteksian kualitas udara pada dualingkungan yang memiliki perbedaan mobilitas sehingga dapat dibandingkan hasi kwalitas udara pada dua daerah tersebut sehingga perlu dibuat prototype pengukur kwalitas udara yang berfungsi untuk mengukur kwalitas udara berbasis internet of things dan nantinya informasi peringatan kwalitas udara akan disebarkan melalui media sosial yaitu Twitter.Sensor yang digunakan adalah DSM501a sebagai sensor pengukur kadar polutan PM10 dan $M Q-8$ dan MQ-2 sebagai sensor tambahan untuk jenis polutan lainnya.
\end{abstract}

Kata kunci : Arduino Uno, DSM501a, InternetofThings,PM10,MQ-8,MQ-2,Twitter.

\section{PENDAHULUAN}

Udara merupakan komponen penting dalam kehidupan manusia dan makhluk hidup lainnya sehingga perlu dipelihara kualitasnya agar dapat berfungsi maksimal untuk mendukung kehidupan yang sehat bagi makhluk hidup (Nugroho, 2009)

Polutan memiliki dampak terhadap kesehatan dan lingkungan (World Health Organization ). Dampak kesehatannya berupa infeksi saluran pernapasan (Bunawas, et al ,1999; World Health Organization; Huboyo dan Sutrisno, 2009; Abdullah, et al ,1999; Yusnabeti, et al ,1999), selain berdampak pada pernapasan juga berbahaya bagi kesehatan jantung (World Health Organization), (Huboyo \& Sutrisno, 2009), dan mengganggu pertumbuhan tulang pada anak-anak (Liu, et al., 2015).Terhadap lingkungan mengganggu jarak pandang (Eiedels-Dubovoi,2002 dalam Sabetghadam dan Ahmadi-Givi, 2014; Wang, et al , 2013, Ram, et al, 2012, Abdullah, et al, 2011) dan kenyamanan berada diluar ruangan.Kondisi lingkungan yang padat penduduk tidak terlepas dari asap baik dari hasil

kemampuan serapan materi polusi yang berbeda

dan akan ditambahkan komponen wi-fi untuk mendukung prototype sehingga berbasis Internet pembakaran hutan, asap rokok dan pembakaran dari kendaraan bermotor

Faktor yang menjadi kendala utama adalah tingginya harga untuk alat pemantau kwalitas udara apalagi yang berkoneksi internet yang bersifat realtime yang memiliki cara kerja ketika kwalitas udara yang melebihi batas ambang baku mutu maka akan secara otomatis pemberitahuan ke stakeholder terkait dalam bentuk informasi singkat berupa twit melalui Twitter.

Internet of Things (IoT) adalah perangkat berbiaya rendah yang mampu mengkoleksi banyak data berinteraksi dengan IoT lain, dan memanfaatkan cloud servis dan cloud base storage.

"Prototype pengukur kwalitas udara PM10 berbasis Internet of Things (IoT)" untuk pengukur kwalitas udara yang berbiaya murah yaitu dengan menggunakan rangkaian arduino uno serta beberapa sensor yang akan digunakan yaitu sensor DSM501a, MQ-8 serta MQ-2 yang masing-masing jenis sensor tersebut memilik

of Things dan diimplementasikan kedalam media informasi berupa Twitter. 


\section{METODE PENELITIAN}

Langkah -langkah algoritma dari proses yang akan dikerjakan adalah :

1.Inisialisasi arduino terhadap sensor

Dalam tahap ini arduino dihubungkan melalui USB sebagai penghubung dari alat menuju ke interface.

2.Proses deteksi polutan

Masuk kehalaman interface dan proses deteksi sensor polutan Proses melewati ambang batas udara Terdeteksi melewati ambang batas udara maka proses berikutnya yaitu penerusan informasi menggunakan media internet.

3.Koneksi ke interface IoT

Informasi diteruskan menggunakan Wi-fi dan akan masuk ke sosial media yaitu Twitter.

4.Pemberitahuan kedalam sosial media.

Cara kerja dari alat pengukur kwalitas polusi udara PM10 berbasis Internet of Things (IoT) menggunakan sensor DSM501a, MQ-8 , MQ-2 adalah sebagai berikut:

1. Universal Serial Bus (USB) sebagai power yang dihubungkan ke laptop untuk memperoleh arus dari tegangan PLN sebesar 220 volt $\mathrm{AC}$, kemudian tegangan diturunkan dan diubah menjadi arus DC sehingga menghasilkan tegangan keluaran sebesar 5 volt.

2. Input Komponen Input dari alat pengukur tingkat polusi udara berbasis mikrokontroler menggunakan sensor DSM501a, MQ-8, MQ2 yang berfungsi untuk mendeteksi materi polutan,kemudian keluaran yang berupa tegangan dikonversi untuk diproses ke mikrokontroler.

3. Proses keluaran berupa tegangan dari sensor dan dikonversi oleh Op-Amp kemudian masuk ke proses di dalam mikrokontroler Arduino Uno . Mikrokontroler ini berisi program yang berfungsi memproses kinerja alat yang nantinya akan dihubungkan melalui ESP 8266 sebagai chips koneksi internet.

4. Output akhir dari prototype ini adalah sebuah pembacaan hasil tingkat polutan yang sebelumnya diproses di dalam mikrokontroler, kemudian diteruskan menjadi informasi yang dibagi melalui salah satu sosial media yaitu Twitter berupa kumpulan karakter "Asap dalam Kondisi bersih", "Asap dalam Kondisi tercemar dan dalam kondisi normal", "Asap melebihi ambang batas baku mutu" sehingga pesan yang ingin disampaikan alat ini mudah dipahami oleh penerima atau Stakeholder.

\section{HASIL DAN PEMBAHASAN}

Implementasi dari prototype mikrokontroller berbasis internet of things ini adalah saat terdeteksi asap yang jumlah kepekatan diluar dari normal maka akan ada pemberitahuan berupa informasi menggunakan sosial media Twitter.

Proses pengiriman informasi melalui Twitter yaitu melakukan pembacaan serial pada modul untuk mengetahui adanya informasi baru. Pengecekan dilakukan dengan mengirimkan perintah AT Command pada modul, jika informasi baru pada modul ditemukan selanjutnya dilakukan pembacaan informasi.Informasi selanjutnya dibandingkan pada perangkat lunak untuk mengetahui perintah seanjutnya melakukan verifikasi id sosial media twitter dan menyimpan nomor setting yang akan dikirimkan sebagai tujuan yang akan dikirimkan informasi jika ada indikasi ketidaknormalan dan polusi udara pada sensor asap dan sensor PM10. Proses pembacaan konsentrasi asap yang terbaca pada sensor MQ2, dimana proses pembacaan dilakukan menggunakan ADC selanjutnya dikonversi menjadi nilai konsentrasi ppm menggunakan persamaan berdasarkan acuan dari datasheet MQ2. Hasil konsentrasi ppm ini menunjukkan kadar asap yang terbaca sehingga jika asap melebihi pengaturan yang ditentukan maka dipastikan pada ruangan tersebut terdapat seorang perokok yang sedang merokok.Kondisi selanjutnya adalah mengirimkan peringatan ke sosial media berupa twitter dengan mengirimkan informasi ke user yang telah disimpan pada sistem, selanjutnya dilakukan pembacaan ADC untuk mengetahui kondisi polutan berdasarkan hasil deteksi sensor asap dan PM10 yaitu DSM501a .Sensor asap ini bekerja berdasarkan jumlah gumpalan yang diterima permukaan sensor, sehingga jika nilai gumpalan asap yang terbaca mencapai nilai pengaturan untuk kondisi 
diatas ambang batas maka sistem memberikan informasi berupa peringatan adanya polusi udara pada ruangan kepada user twitter yang telah didaftarkan, begitu seterusnya sampai kondisi udara kembali ke kondisi normal.

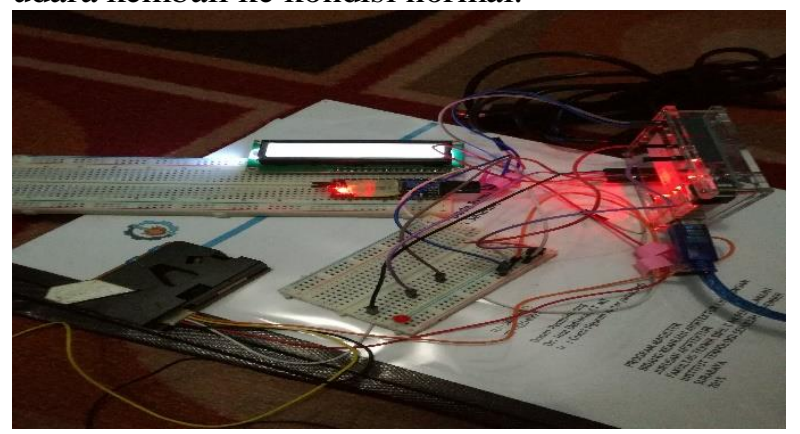

Gambar 1.Prototype saat mendeteksi asap

\section{KESIMPULAN}

Kesimpulan dari pengembangan Prototype mikrokontroller ini yaitu dapat diuraikan sebagai berikut:

1. Hasil pengujian perangkat sensor pada lingkungan didalam ruangan secara langsung dapat terdeteksi dengan menggunakan perangkat sensor yang digunakan dan siap digunakan dalam sistem pengendalian dapat dikembangkan untuk kondisi yang luas cakupannya.

2. Sensor asap rokok yang dirancang menggunakan MQ2 bertugas mendeteksi asap rokok dengan perbahan resistansi terhadap kepekatan asap kemudian dikonversi menjadi tegangan agar dapat dibaca ADC.

3. Visualisasi data yang digunakan memang bukan merupakan hal yang baru. Penggunaan visualisasi data melalui media sosial telah umum digunakan sebagai media informasi serta pengawasan kualitas udara dan dikembangkan berbasis internet of things sebagai pengembangan sarana untuk pengembangan yang baik dapat meningkatkan penyampaian informasi.

\section{REFERENSI}

Efendi Ilham. (2014). Pengertian dan Kelebihan Arduino. Retrieved from http://www.itjurnal.com

Gindo, A., \& Hari, B. (2012). Pengukuran Partikel Udara Ambien (Tsp, PM10, PM2, 5) Di Sekitar Calon Lokasi Pltn Semanjung Lemahabang. Prosiding seminar nasional teknologi pengolahan limbah VI (pp. 220-227). Pusat Penelitian Ilmu Pengetahuan dan Teknologi - RISTEK.

Hamada JI,Yamanaka MD,Matsumoto J,Fukao S, Winarso PA,Sribimawati T. (2002). Spatial and Temporal Variances of the rainy session oper indonesia and their link to ENSO. Journal of Meteorologycal Society Japan, 285-310.

Huboyo, H. S., \& Sutrisno, E. (2009). Analisis Konsentrasi Particulate Matter 10 (PM10) pada Udara Diluar Ruang (Studi Kasus : Stasiun Tawang - Semarang). TEKNIK, 30(1), 44-48.

Kistinnah I ; Lestari ES. (2006). Biologi Makhluk Hidup dan Lingkungannya. Jakarta: Pusat Perbukuan departemen Pendidikan Nasional.

Liu, C., Fuertes, E., Flexeder, C., Hofbauer, L. C., Berdel, D., Hoffmann, B., . . . Heinrich, J. (2015). Associations betweens Ambient Air Pollution and Bone Turnover Markers in 10-year old children: Result from the GINIplus and LISAplus Studies. International Journal of Hygiene and Environmental Health, 218, 58-65.

Oxford Dictioneries. (2013, September 8). pollutant - definition of pollutant in English from the Oxford dictionary. Retrieved from Oxford Dictioneries: http://www.oxforddictionaries.com/us/d efinition/american_english/pollutant

Satsangi, P. G., Kulshrestha, A., Taneja, A., \& Rao, P. S. (2011, 8). Measurements of PM10 and PM2. 5 in aerosols in Agra, a semi-arid region of India. Indian Journal of Radio \& Space Physics, 40, 203-210.

World Health Organization. (n.d.). Public health, environmental and social determinants of health (PHE). Retrieved 4 10, 2016, 
from World Health Organization: http://www.who.int/phe/air_quality_ q\&a 